\title{
Os comunistas e a Constituinte de 1946 - por ocasião do 60ำ aniversário da Constituição de 1946
}

ANITA LEOCADIA PRESTES*

Resumo: Neste artigo faz-se uma apreciação do contexto sócio-político presente no Brasil durante o ano de 1945. Destaca-se a atividade dos comunistas, voltada para a luta pela convocação de uma Assembléia Constituinte livremente eleita. Com a convocação de eleições para a Assembléia Constituinte, os comunistas elegem uma bancada, cuja atuação na Constituinte de 1946 é analisada no artigo.

Abstract: This is an analysis of the sociopolitical context present in Brazil during the year 1945. Emphasis is given to the activity of the communists, directed to the fight for the convocation of a freely elected Constituent Assembly. With the convocation of elections for the Constituent Assembly, the communists elected a group of representatives, whose performance in the Assembly of 1946 is analyzed in this article.

Palavras-chave: Constituinte de 1946. PCB (Partido Comunista do Brasil). Bancada comunista.

Key words: Constituent Assembly of 1946. PCB (Communist Party of Brazil). Communist representatives.

\section{A derrota do nazifascismo e o processo de democratização do país}

A vitória dos Aliados na Segunda Guerra Mundial seria acompanhada, no Brasil, pelo processo de "abertura" ou, melhor, de descaracterização e desarticulação do Estado Novo. Nas palavras de M. V. Benevides, havia uma "galopante desagregação das forças estadonovistas" (Benevides, 1981, p. 24).

* Doutora em História Social pela Universidade Federal Fluminense e professora de História do Brasil no Departamento de História da UFRJ. E-mail: anitaprestes@ifcs.ufrj.br

Estudos Ibero-Americanos. PUCRS, v. XXXII, n. 2, p. 171-186, dezembro 2006 
O Estado Novo entrara em crise, "que começou a delinear-se com maior clareza no ano de 1944, embora já estivesse colocada (...) desde a consolidação do alinhamento do Brasil aos EUA dois anos antes", conforme é assinalado por L. F. Corsi (2000, p. 274).

Ângela de C. Gomes destaca que, a partir de 1942/43, o Estado Novo tentaria a "consolidação de um verdadeiro pacto social com as classes trabalhadoras" (Gomes, 1988, p. 288). Dentro dessa perspectiva, surgiu para o regime a questão político-eleitoral, ou seja, a preocupação com a criação de partidos e, em particular, com a formação de um partido que angariasse apoios à continuidade política de Vargas (Gomes, 1988, p. 289-292). O insucesso de tal iniciativa teria como conseqüência "um deslocamento de ênfase, da questão da construção de um partido, para a questão da reforma constitucional" (Gomes, 1988, p. 292). Tratava-se de, a partir de Carta de 1937, implementar um conjunto de medidas com o objetivo de legalizar o regime, assegurando, contudo, a continuidade de Vargas. "O ano de 1944 poderia ser entendido como o ano da campanha eleitoral de Vargas" (Gomes, 1988, p. 299).

Frente às "pretensões democratizantes de Getúlio Vargas, cujas posições teriam começado a mudar com as perspectivas da vitória dos Aliados contra o Eixo", é que os liberais, que viriam a agrupar-se na UDN (União Democrática Nacional), em abril de 1945, procuraram "recuperar a iniciativa política" (Benevides, 1981, p. 35). Tratava-se de um movimento iniciado com o lançamento do "Manifesto dos Mineiros", a 24/10/1943, cuja importância advinha do fato de ter sido a "primeira manifestação ostensiva, coletiva e assinada, organizada por membros das elites liberais, até então ausentes em qualquer contestação pública" (Benevides, 1981, p. 34).

Respondendo ao "Manifesto dos Mineiros", em discurso pronunciado a 10/11/1943, por ocasião do sexto aniversário do Estado Novo, Getúlio Vargas prometia, para quando terminasse a guerra, reajustar "a estrutura política da nação", fazendo "de forma ampla e segura as necessárias consultas ao Povo Brasileiro" (Silva, 1976, p. 77).

Entretanto, já no final de 1944, os grupos oposicionistas, sob a liderança das elites liberais, tratariam de articular a candidatura à presidência da República do Brigadeiro Eduardo Gomes (Silva, 1976, p. 107), postulante a uma eleição que ainda não fora colocada em pauta. Tratava-se do "candidato irrevelado", nas palavras de José Américo de Almeida, que, em célebre entrevista ao Correio da Manhã ${ }^{1}$ - cujo resultado imediato fora o fim da censura à imprensa -, afirmara que "as forças políticas nacionais já têm um candidato", sem, contudo, nomeá-lo (Silva, 1976, p. 86, 93, 96).

1 Cf. Correio da Manhã, Rio de Janeiro, 22/02/1945, p. 14, apud Silva (1976, p. 83-96). 
Havia se criado no País uma nova situação, com a articulação de uma candidatura de oposição e o conseqüente abalo produzido nos planos governistas de assegurar o continuismo de Vargas. O governo seria levado "a pensar seriamente em não mais condicionar as eleições ao fim da guerra" e "para esta solução também contribuiu o contexto internacional, especialmente a realização das eleições nos Estados Unidos, dando vitória a Roosevelt" (Gomes, 1988, p. 301). Conforme é assinalado por R. Maranhão,

Getúlio, já no começo de 1945, procurou tomar das mãos dos liberais a iniciativa da redemocratização, quando percebeu que os rumos da guerra mundial, e a colaboração entre as grandes potências vitoriosas, estimulavam um clima internacional de democracia e colaboração política. ${ }^{2}$

Diante da nova situação, a 28/02/1945, Vargas assinava a Lei Constitucional n. 9, que também seria chamada de Ato Adicional pelos políticos e pelos jornais. Na realidade, era uma reforma constitucional bastante tímida: além de modificar alguns artigos e parágrafos referentes à intervenção federal nos estados, a Lei fixava o prazo de 90 dias para a marcação de eleições diretas para a presidência da República, Câmara dos Deputados, Conselho Federal (correspondente ao antigo Senado Federal), governadores e assembléias legislativas estaduais. Eram ainda modificados o funcionamento e a composição do Poder Legislativo e as normas para a realização de reformas constitucionais. Pode-se dizer que "era a primeira iniciativa concreta de Vargas na tentativa de comandar a redemocratização" (Silva, 1976, p. 112).3

Nesse momento, o governo Vargas não cogitava de convocar uma constituinte. Sua tática foi a de "marchar para a democratização procurando (...) romper o menos possível com a estrutura do Estado Novo" (Silva, 1976, p. 109). Seria, forçado, contudo, pela pressão interna da opinião pública nacional e pela marcha dos acontecimentos na arena internacional, a tomar medidas de caráter cada vez mais democratizante. Se a censura à imprensa é abolida em fevereiro de 1945, com a entrevista de José Américo, em abril o governo estabelece relações diplomáticas com a URSS e decreta a anistia para os presos e perseguidos políticos (Carone, 1977, p. 319326). Em maio, dá-se a extinção do DIP (Departamento de Imprensa e Propaganda) - mais um fator que contribui para o processo de democratização (Silva, 1976, p. 20).

2 Maranhão, Ricardo. A queda da Ditadura, Movimento, São Paulo, n. 18, 03/11/1975, p. 9-14, apud Silva (1976, p. 108).

3 Cf. Carone (1976, p. 111-117). 
No início do ano, são lançadas a candidatura presidencial de Eduardo Gomes, pela oposição, e a de Eurico Gaspar Dutra - em resposta à candidatura oposicionista -, pelo governo, embora a Lei Eleitoral só viesse a ser editada em maio de 1945. O pleito, pelo voto direto, para presidência da República, Conselho Federal e Câmara dos Deputados era marcado para 2 de dezembro, sendo estabelecidas as condições para a formação de partidos políticos, que passariam a congregar as diversas forças políticas então presentes (Silva, 1976, p. 150-154).

Em julho, o Partido Comunista (PCB) é legalizado (Benevides, 1981, p. 54), embora na prática já viesse atuando abertamente desde antes, principalmente a partir da grande manifestação, realizada no Rio de Janeiro a 21/04, em homenagem a F. D. Roosevelt, falecido no início desse mês. Na ocasião, na presença do embaixador norte-americano e com a participação de Luiz Carlos Prestes, recém saído da prisão, o PCB conquistou a legalidade nas ruas, obtendo amplo reconhecimento popular, que seria reafirmado em sua primeira apresentação pública, no célebre comício no estádio do Vasco da Gama (Rio de Janeiro), realizado a 23/05/1945 (Segatto, 1982, p. 75-77), 4 da mesma forma que em numerosas outras manifestações e atos públicos por todo o país (Segatto, 1982, p. 77-81; Carone, 1977, p. 240-249).

O processo de "abertura" democrática avançava como bola-deneve. Vargas, tentando sempre a continuidade do regime e, em particular, sua permanência no poder, buscava maneiras de aproximar-se dos trabalhadores. Com tal objetivo, adotaria medidas como a "Lei Malaia", ou lei antitruste, de 22/06/1945, que, num contexto de grande descontentamento popular e de uma vaga de greves por melhores salários e condições de vida e trabalho, visava "caracterizar o (...) governo como nacionalista e jogar a culpa da crescente inflação, que afligia o grosso da população, nos empresários" (Corsi, 2000, p. 277). A lei antitruste teve o papel de suscitar grande entusiasmo popular e provocar simpatia das forças de esquerda, embora, como é mostrado por L. F. Corsi, visasse, sobretudo, "combater a inflação e os setores que com ela vinham lucrando" (Corsi, 2000, p. 279).

Em contrapartida, a oposição se une em "uníssono repúdio" (Benevides, 1981, p. 54) contra a política getulista de aproximação com as massas trabalhadoras e de edição de uma legislação antitruste, que poderia atingir os interesses do capital estrangeiro no Brasil, embora seja necessário considerar que o nacionalismo de Vargas deixara de ser "estritamente econômico, voltado para o desenvolvi-

4 Prestes, Luiz Carlos. Declarações à autora, anos 1980. 
mento", e passara a ser "um instrumento de mobilização da classe trabalhadora" (Corsi, 2000, p. 293). Da mesma forma, "o caráter nacionalista da lei dirigia-se fundamentalmente ao público interno e não ao capital estrangeiro, que continuou sendo considerado vital para o desenvolvimento da economia" (Corsi, 2000, p. 279-280). É inegável, contudo, que os setores empresariais - particularmente os ligados ao capital estrangeiro - sentiram-se diretamente atingidos (Carone,1976, p. 196; Carone, 1977, p. 104).

Esta a razão por que, com a queda de Getúlio Vargas, em 29/10/45, a lei antitruste seria imediatamente revogada (Carone, 1977, p. 104). De acordo com documentos do National Archives, em Washington, havia interesse direto americano na queda de Vargas, e o embaixador dos EEUU no Brasil, Adolf Berle, mostrava-se preocupado com

a viabilidade de um presidente brasileiro que, além de contar com o apoio popular, desenvolvesse uma política econômica prejudicial como a legislação antitruste - aos interesses das classes produtoras, naturalmente convergentes com a expansão do capital americano (Benevides, 1981, p. 55).

As medidas liberalizantes do regime varguista alarmavam os setores mais conservadores da oposição; estes contavam com o apoio dos liberais agrupados em torno da UDN e de alguns setores da intelectualidade de "esquerda", que "não percebiam o caráter antipopular de sua reação às políticas getulistas de aproximação com as massas e de renovação na área econômica". Assim, a partir de abril, "a grande imprensa passa a dirigir suas críticas a Getúlio não por ser um ditador, mas por 'não controlar a classe operária' e 'permitir que seu Ministro do Trabalho, Marcondes Filho, encorajasse as greves'" (Benevides, 1981, p. 54).

Com a aproximação de Vargas das massas trabalhadoras e frente à democratização que o regime varguista era forçado a patrocinar, os liberais, num aparente paradoxo, voltavam-se para os militares, numa postura francamente golpista. Otávio Mangabeira, presidente da UDN, declarava, em junho de 1945: "Penso que as Forças Armadas estão no dever de intervir na atual situação brasileira. Vou adiante: é seu dever intervir (...) são as únicas forças que tem força real para acudir em defesa da nação". ${ }^{5}$ Como é assinalado por M. V. Benevides, "o liberal Otávio Mangabeira (...) defenderia sempre a intervenção militar "para salvar a democracia, esta tenra plantinha'" (Benevides, 1981, p. 55, nota 30).

5 Mello Franco, Virgílio. A Campanha da UDN. Rio de Janeiro, Valverde, 1946, p.305, apud Benevides (1981, p. 55). 
A posição do Brigadeiro Eduardo Gomes, candidato da UDN, não seria diferente. Sua defesa da renúncia de Getúlio Vargas não passaria de uma forma camuflada de golpismo. Em sua primeira entrevista pública, a 16/04/1945, o Brigadeiro afirmava que, dado o estado de decomposição em que se encontrava o Estado Novo, "é urgente o restabelecimento no Brasil da ordem constituída" e "não é possível esperar que esta ordem resulte de um processo eleitoral conduzido, dirigido e manipulado pela própria ditadura". Por isso, seria necessário que a Constituição de 34 fosse restaurada e, uma vez atingido tal objetivo, "não se compreende mais a permanência do Sr. Getúlio Vargas no poder" (Carone, 1976, p. 121).

A proposta do candidato da UDN era de que, com a renúncia do chefe de Estado, o poder fosse transferido ao Presidente do Supremo Tribunal Federal (Carone, 1976, p. 122), medida que não seria aceita por Vargas (Carone, 1977, p. 327). Ficava implícita a intenção golpista do Brigadeiro e de seus seguidores, pois a recusa do chefe do governo de deixar o poder só poderia ter como corolário a deflagração do golpe militar. Golpismo que ficaria comprovado na prática, a 29/10/1945, quando Vargas foi obrigado a renunciar pelos generais, liderados por Góis Monteiro - e com a participação dos dois candidatos à Presidência, Dutra e Eduardo Gomes - contando com o apoio da UDN e das forças mais conservadoras do país, temerosas principalmente das medidas liberalizantes que vinham sendo adotadas pelo Governo.

Na realidade, Eduardo Gomes e Eurico Dutra, chefes militares e candidatos presidenciais respectivamente pela UDN e pelo PSD, ${ }^{6} \mathrm{O}$ primeiro oposicionista e o segundo governista, estavam juntos na hora de barrar a aproximação de Vargas dos setores populares, assim como as medidas democratizantes adotadas pelo seu governo. ${ }^{7}$ O golpe de 29/10/45 viria confirmar o que L. C. Prestes dissera ainda em abril, ao sair da prisão: "Dificilmente poderia haver dois candidatos tão semelhantes", referindo-se ao Brigadeiro e ao Gen. Dutra (Carone, 1976, p. 519). E repetiria mais tarde, em célebre debate com Otávio Mangabeira, no plenário da Assembléia Constituinte: “(...) o Sr. Brigadeiro Eduardo Gomes, junto com o General Dutra, comandava o golpe, do Quartel General nesta Capital... (...). Comandou o

6 PSD - Partido Social Democrático, criado por Vargas para dar sustentação ao governo, cujo candidato à Presidência era o Gen. Dutra.

7 Cabe lembrar que, enquanto o Estado Novo esteve no auge, Dutra foi um de seus principais sustentáculos e Eduardo Gomes manteve-se em silêncio, ocupando lugar de destaque na Força Aérea do país. Ambos se uniram para derrubar o Estado Novo, quando este já havia mudado de caráter e o governo Vargas tomara medidas de cunho popular e democratizante. 
golpe de 29 de outubro, do lado do General Dutra. São ambos iguais: tão reacionários um quanto o outro". 8

\section{Os comunistas, a luta pela Assembléia Constituinte e o golpe de 29/10/1945}

Para Luiz Carlos Prestes, assim como para os comunistas que, a partir da Conferência da Mantiqueira (agosto de 1943), se organizaram sob a sigla do PCB, desde o início de 1945 e, em particular, desde o lançamento da candidatura do Brigadeiro Eduardo Gomes, o processo de conquista efetiva da democracia no país só poderia ter êxito por meio de uma Assembléia Constituinte livremente eleita pelo povo brasileiro, que viesse a elaborar uma Constituição democrática.

Para os comunistas, nas condições concretas daquele momento histórico, a Constituinte seria o único meio capaz de levar à implantação de um regime democrático no Brasil, sepultando a Constituição de 1937 e as instituições do Estado Novo e, ao mesmo tempo, impedindo a consumação de um golpe militar por parte das forças mais conservadoras, golpe este que viesse a reverter o processo de democratização inaugurado por Vargas.

Ainda em sua primeira entrevista à imprensa, ao sair da prisão, L. C. Prestes condenaria a proposta do Brigadeiro de "substituir o ilegal pelo ilegal, o ilegítimo pelo ilegítimo", ou seja, Getúlio Vargas pelo presidente do Supremo Tribunal Federal, homem de confiança do chefe do governo. Para o secretário-geral do PCB, "a única solução cabível é a da legitimação de órgãos governamentais por meio de um parlamento que delibere como Constituinte". ${ }^{9}$

Tal posição continuaria a ser defendida pelos comunistas nos meses seguintes. No discurso pronunciado no grande comício realizado no estádio do Vasco da Gama a 23/05/45, Prestes combatia a tese da renúncia de Vargas, afirmando que

a oposição exige que o Sr. Getúlio Vargas abandone o cargo, para que seja mantida a paz interna. Mas será esse realmente o caminho democrático da ordem, da paz, e da união nacional? Não terá, ao contrário, razão o Sr. Getúlio Vargas ao afirmar que seu dever é manter a ordem para levar o país a eleições livres e honestas e entregar o poder ao eleito da Nação? (Prestes, s. d., p. 89).

Ao mesmo tempo, o dirigente comunista acrescentava:

8 Mangabeira, Otávio. Discursos Parlamentares. Brasília: Câmara dos Deputados, 1978, p.401, apud Benevides (1981, p. 51).

9 Entrevista de L.C. Prestes, Folha da Manhã, 27/04/1945, apud Carone (1976, p. 522). 
O que queremos é chegar, através da União Nacional, à verdadeira democracia, antes e acima de tudo a uma Assembléia Constituinte, de que participem os legítimos representantes do povo, assembléia democrática que efetivamente apoiada pelo povo, organizado em seus partidos políticos e comitês populares democráticos, possa, livre e soberanamente, discutir e votar a Carta Constitucional que almejamos, a Lei fundamental que permita o progresso da Pátria e nos assegure, a todos nós, e para sempre, os grandes, sagrados e inalienáveis direitos do homem e do cidadão, a par dos direitos que todos devemos ter ao trabalho, à saúde, à instrução e cultura, ao bemestar, assim como ao socorro e ajuda na doença, na invalidez e na velhice (Prstes, s. d., p. 92).

Em julho daquele mesmo ano, no também célebre comício do Estádio do Pacaembu (São Paulo), L. C. Prestes voltaria a bater na mesma tecla, afirmando que os comunistas tudo fariam para

unificar as mais amplas camadas sociais, visando antes e acima de tudo, levar ao Parlamento a que se refere o Ato Adicional n. 9, ou à Assembléia Constituinte, que preferimos, o maior número possível de genuínos representantes do povo, capazes de defender a democracia (...) (Prestes, s. d., p. 118).

O secretário-geral do PCB insistia ainda na denúncia do golpe em gestação, esclarecendo que "se apoiamos o governo, é porque marcha para a democracia" e "nisso não há manobra oculta", acrescentando que "nosso apoio é franco, aberto e decidido, porque vemos os pregadores da desordem, dos golpes 'salvadores', agentes mascarados, conscientes ou inconscientes, (...) da provocação fascista" (Prestes, s. d., p. 112).

Um mês depois, no Informe Político apresentado em nome da Comissão Executiva ao Pleno do Comitê Nacional do PCB - o "Pleno da Vitória" -, novamente afirmava-se que

o melhor caminho para a efetiva democratização do país não é (...) o estabelecido pelo Ato Adicional. Reclamamos a convocação de uma Assembléia Constituinte, em que os verdadeiros representantes do povo possam livremente discutir, votar e promulgar a Carta Constitucional que pede a Nação (Prestes, s. d., p. 156).

Ao justificar a defesa da convocação imediata da Constituinte e o adiamento da eleição presidencial para depois da promulgação de uma nova Carta, a direção do PCB dava a seguinte explicação: 
O governo que aí temos é um governo de fato e qualquer eleição presidencial, enquanto estiver em vigor a Carta de 1937, inaceitável para qualquer patriota consciente, nada mais significa do que a simples mudança de homens no poder, a substituição de um governo de fato por outro governo de fato, igualmente armado dos poderes vastos e arbitrários que confere ao Executivo a referida Carta. (Prestes, s. d., p. 156).

Em setembro de 1945, Prestes reafirmaria as mesmas posições quanto à necessidade de promover eleições gerais para a Constituinte, expressando a confiança de que "as forças populares organizadas juntamente com o Partido Comunista" viessem a eleger uma Assembléia com os "legítimos representantes do povo", aos quais caberia proclamar "uma constituição efetivamente democrática, impedindo, por exemplo, que o presidente da República, se eleito em 2 de dezembro, ${ }^{10}$ exercesse o governo com os poderes fascistas da carta de 1937, inclusive para dissolver o próprio Parlamento". ${ }^{11}$

Em outubro, os comunistas intensificariam as denúncias contra o golpe em preparação. Prestes declarava que "o Partido Comunista está realmente decidido a defender o Governo contra quaisquer perturbações e insistiremos na campanha pela Constituinte, esperando que, dentro de poucos dias, o Sr. Getúlio Vargas satisfaça a vontade do povo". ${ }^{12}$

Os documentos da época revelam que, em momento algum, o PCB ou L. C. Prestes defenderam a palavra de ordem de "Constituinte com Getúlio", bandeira do movimento queremista. ${ }^{13}$ "Queremos Constituinte com Getúlio" era a consigna de tal movimento, que, com o beneplácito e o incentivo do próprio Vargas, se batia pelo seu continuismo.

Diferentemente do que foi difundido pelos seus detratores e, mais tarde, consagrado em grande parte dos escritos existentes sobre o assunto -, os dirigentes comunistas jamais defenderam a continuidade de Vargas no poder. Pelo contrário, lutaram por eleições presidenciais efetivamente democráticas, entendendo que para tal era necessário que as mesmas se realizassem numa nova situação institucional, livre do autoritarismo da Carta estadonovista de 1937.

10 2/12/1945 - data .prevista para as eleições.

11 Entrevista de L. C. Prestes, Diário de São Paulo, 09/09/1945 e Folha da Manhã, 09/09/1945, apud Carone (1977, p. 336-337).

12 Entrevista de L. C. Prestes, Folha da Manhã, 23/10/1945, apud Carone (1977, p. 337).

13 Sobre o queremismo, cf., por exemplo, Carone (1977, p. 332-336). 
Para o PCB, apoiar Vargas, exigindo concomitantemente a convocação da Assembléia Constituinte, era o meio de evitar o golpe das forças mais conservadoras - aquelas que desejavam impedir a aproximação de Getúlio com as massas e travar o processo de democratização que vinha sendo por ele promovido, apesar das vacilações e limitações evidenciadas. Para os comunistas, tratava-se, portanto, de dar sustentação ao governo existente, que vinha tomando medidas de "abertura" do regime, e pressioná-lo no sentido da realização de eleições livres para a Constituinte, em que fosse elaborada e promulgada uma nova Lei Magna, representativa da correlação de forças presentes no País. Dessa forma, o presidente da República a ser eleito iria governar respeitando os preceitos de uma Constituição democrática, expressão da vontade nacional.

O crescente conflito entre o continuismo de Vargas, fortalecido pela ofensiva queremista, e as pretensões golpistas da UDN e de setores da oficialidade do Exército terminaria por levar ao golpe militar, que afastou Vargas do poder. Para tal desfecho foi importante o apoio dos EEUU, cujo embaixador Adolf Berle deixara clara a simpatia do seu governo pelas forças que se articulavam contra Vargas (Carone, 1977, p. 338-341).

Os fatos são conhecidos (Carone, 1977, p. 337-349), sendo necessário considerar que a divisão do Exército facilitou a atividade golpista da oposição civil e, finalmente, sua aliança com o General Góis Monteiro. Este último, conforme é assinalado por E. Carone, "percebendo a mudança aceita liderar definitivamente a corrente eleitoral, para não ser deslocado do poder, como será o caso de Getúlio Vargas" (Carone, 1977, p. 344). Góis Monteiro, numa atitude oportunista, assumiria o comando do movimento armado que levou Vargas à renúncia, visando "permanecer à frente da classe para não perder a sua hegemonia, que ele vem mantendo desde 1930" (Carone, 1977, p. 346; Carone, 1985, p. 10).

O real sentido do golpe torna-se claro quando se verifica que Vargas, após a renúncia, embarcava cercado de garantias para suas fazendas no Rio Grande do Sul, enquanto os comunistas seriam alvo da repressão policial. As sedes do PCB foram invadidas e depredadas, seus dirigentes perseguidos e presos. ${ }^{14}$ Prestes recordaria que "os tanques, os canhões e as metralhadoras não foram dirigidos contra o Sr. Getúlio Vargas, mas contra a sede do Partido Comunista. Foi o nosso Partido o único que sofreu violências, naquela noite e nos dias que se seguiram" (Benevides, 1981, p. 51).

14 Cf. Manifesto do PCB, 03/11/1945, Tribuna Popular, 06/11/1945, apud Carone (1982, p. 61). 
Fica difícil, portanto, concordar com certas avaliações positivas do golpe de 1945, que o consideram progressista e até mesmo expressão das aspirações mais profundas das classes populares. Avaliar o golpe contra Getúlio como uma vitória das forças democráticas sobre a ditadura estado-novista pode servir para justificar a atuação dos liberais da UDN e dos generais golpistas, mas não contribui para explicar a essência dos acontecimentos então em curso.

A 29/10/1945 foi "derrubado" um Estado Novo que já não mais existia, pois o regime autoritário de 1937 mudara de caráter. $\mathrm{Na}$ realidade, ocorrera uma tentativa reacionária e conservadora de reverter o processo de democratização da sociedade brasileira, que vinha sendo promovido com a permanência de Vargas no poder. Diante da pressão significativa de múltiplos fatores nacionais e internacionais, dentre os quais cabe destacar o movimento de opinião pública no Brasil contrário ao nazifascismo, a vitória da URSS e dos Aliados na Guerra e as pressões do Governo Roosevelt, interessado no alinhamento do Brasil com os EEUU (Prestes, 2001), Vargas soubera adaptar-se à nova situação no país e no mundo, aceitando e procurando patrocinar a liberalização do regime estado-novista.

O sucesso do golpe não foi, entretanto, total, dada a força de movimento favorável à democratização do país. A repressão aos comunistas teve logo que cessar. Em Manifesto lançado a 3/11, o PCB afirmava que

o passo decisivo no caminho da Democracia, a solução pacífica e unitária para o problema político está (...), agora mais do que antes, na imediata modificação do Ato Adicional, Lei Constitucional n. 9, para que, afastadas as candidaturas presidenciais, seja convocada no menor prazo possível uma Assembléia Constituinte, onde os representantes do povo discutam, votem e promulguem a Carta Constitucional democrática que reclama a Nação. ${ }^{15}$

A 12/11, José Linhares, o novo presidente da República - que na qualidade de presidente do Supremo Tribunal Federal assumira o poder - assinava decreto convocando eleições para a Assembléia Constituinte, conforme a proposta dos comunistas. Proposta que também havia sido apoiada pelos queremistas nos meses que antecederam o golpe, ainda que estes, como é sabido, defendessem "Constituinte com Vargas". Entretanto, o pleito presidencial era mantido, concomitantemente com as eleições para a Consti-

15 "Manifesto do PCB",03/11/1945, Tribuna Popular, 06/11/1945, in Carone (1982, p. 62). 
tuinte, na data anteriormente fixada de 2 de dezembro. Neste ponto, os setores populares liderados pelos comunistas foram derrotados, o que levou o PCB a lançar candidato próprio às eleições presidenciais, o engenheiro Yeddo Fiúza (Silva, 1976, p. 274-276; Carone, 1985, p. 13-14).

Como sempre no Brasil, chegava-se a um compromisso, resultado da correlação de forças então presente: nem os setores democráticos e populares, junto aos quais o PCB adquiria penetração crescente, tiveram força para alcançar o adiamento das eleições presidenciais para depois da promulgação da nova Carta, nem os setores golpistas de direita puderam reverter inteiramente o processo de democratização da sociedade brasileira, apesar de sabidamente tal processo ter se mostrado frágil e inconseqüente, mesmo com a promulgação da Constituição de 1946, em que importantes conquistas democráticas ficariam inscritas.

\section{A bancada comunista na Constituinte de 1946}

Desde o início dos trabalhos da Constituinte, a bancada comunista - composta pelo senador Prestes e 14 deputados - iria destacar-se pela defesa permanente da democracia e dos direitos democráticos, travando, por exemplo, luta ferrenha pela imediata revogação da Constituição de 1937, objetivo que não seria alcançado, dada a maioria conservadora da Assembléia de 1946.

Uma vez elaborado o Projeto da Constituição, a bancada comunista apresentou 180 emendas ao mesmo, indicando vários de seus aspectos conservadores (Braga, 2003, p. 35). A declaração de voto da bancada comunista foi lida por Prestes e, como assinala Sérgio Soares Braga, nesse discurso Prestes "procura articular as propostas elaboradas pelo PCB à Constituinte com a análise que o partido fazia da sociedade brasileira da época, centrando seu foco de atenção na abordagem da questão agrária e da sua relação com o processo de democratização do País" (Braga, 2003, p. 35). Quanto às emendas apresentadas pelos comunistas, na sua maioria, foram rejeitadas ou indeferidas pelo presidente da Assembléia. No entanto, como escreve o mesmo autor, "permanecem como documento do caráter avançado e progressista da luta empreendida pelos comunistas naquele parlamento conservador" (Braga, 2003, p. 35). 
Por ocasião do transcurso do $1^{\circ}$ aniversário da promulgação da Constituição de 18 de setembro de 1946, Prestes reconheceria, em discurso proferido no Senado, que "se não fizemos uma Constituição progressista, promulgamos uma Constituição democrática" (Braga, 2003, p. 649). Indiscutivelmente, para tal resultado, a contribuição da bancada comunista fora decisiva. Há que lembrar que a luta pela democratização do País fazia parte da política do PCB (Partido Comunista do Brasil). Há que assinalar que o documento básico que orientou a atuação dos comunistas na Constituinte foi o informe político apresentado por Prestes no Pleno Ampliado da Direção Nacional do PCB, realizado em janeiro de 1946. Entre os pontos mais importantes desse documento, deve-se destacar a defesa do direito de voto para todos os cidadãos brasileiros, maiores de 18 anos, inclusive analfabetos, soldados e marinheiros. Da mesma forma, a garantia efetiva das liberdades de opinião, de consciência, de reunião, de associação, inclusive política, de manifestação de pensamento, etc. A completa igualdade de direitos sem distinção de sexo, religião ou nacionalidade. E muitas outras demandas democráticas (Braga, 2003, p. 30-32), como foi o caso da autonomia municipal, vista por Prestes como "a base, o fundamento dessa Democracia", sendo que uma "Democracia em que, sob qualquer pretexto, (...) não se possa contar realmente, com o governo próprio de uma circunscrição básica, como é o município -, não merece esse nome de democracia" (Braga, 2003, p. 277).

Ao defender insistentemente a consagração dos mais amplos direitos democráticos na Constituição e, após a sua promulgação, o respeito àqueles preceitos democráticos que nela haviam sido incorporados, Prestes declarava que "não é capitulando diante dos reacionários que se defende a democracia. A maneira de defendêla consiste em lutar por ela até o fim e lutar decisivamente" (Braga, 2003, p. 276). Essa foi a postura dos parlamentares comunistas na Constituinte e, posteriormente, na Câmara e no Senado Federais, o que se evidencia nos discursos pronunciados por Prestes e pelos deputados da bancada comunista.

O problema da terra no Brasil - o monopólio da propriedade privada da terra -, visto como um dos grandes entraves à democratização do País, constituiu uma das principais questões levantadas pelos comunistas nos debates parlamentares então travados. Tendo votado contra o Projeto de Constituição que seria aprovado pela maioria conservadora da Assembléia Constituinte, a bancada comunista propôs emendas visando à garantia do direito de propriedade, "desde que não seja exercido contra o interesse social ou coletivo ou quando anule, na prática, as liberdades individuais 
proclamadas nesta Constituição ou ameacem a segurança nacional", e afirmando que esse direito e "seu uso serão condicionados ao bem-estar social, de modo que permitam a justa distribuição deles com iguais oportunidades para todos" (Braga, 2003, p. 258). Ao mesmo tempo, os comunistas propunham outras emendas com o objetivo de garantir "a fixação do homem no campo, tomando as medidas necessárias para o fracionamento dos latifúndios, para o desenvolvimento das pequenas propriedades, para a criação de novos centros de população agrícola, com as terras e as águas que lhes sejam indispensáveis para o fomento da agricultura e para evitar a destruição dos elementos naturais e os danos que a propriedade possa sofrer em prejuízo da sociedade" (Braga, 2003, p. 259). Emendas que seriam rejeitadas pela maioria reacionária com assento na Constituinte de 1946.

Nos discursos de Prestes a reforma agrária é um tema recorrente. Afirmava ele: "sem uma redistribuição da propriedade latifundiária, ou em termos mais precisos, sem uma verdadeira reforma agrária, não é possível debelar grande parte dos males que nos afligem" (Braga, 2003, p. 247). Palavras premonitórias e reveladoras, que se mantêm atuais, demonstrando não só a postura pioneira dos comunistas na luta pela reforma agrária, como a justeza dessa luta, encampada hoje por amplos setores da sociedade brasileira, apesar da encarniçada resistência oferecida de maneira firme e persistente pelos grandes proprietários de terra e seus representantes nos poderes da República.

Durante os trabalhos da Constituinte, os comunistas se bateram pela definição precisa, sem subterfúgios, dos "direitos sociais", posicionando-se claramente contra o estabelecimento de quaisquer restrições ao direito de greve (Braga, 2003, p. 38). Frente ao DecretoLei n. 9.070, de 15 de março de 1946, baixado pelo Poder Executivo, e que na prática feria o direito de greve, a bancada comunista propôs sua desaprovação, declarando que "o princípio relativo ao direito de greve deve ser proclamado numa nação que se organiza democraticamente, mesmo que o país conte - como contamos - com uma justiça própria aparelhada para dirimir contendas entre empregados e empregadores, com base na legislação social" (Braga, 2003, p. 406). Mais uma vez, entretanto, um requerimento dos comunistas seria rejeitado (Braga, 2003, p. 427-430). Na Constituição de 1946, ficaria inscrito o direito de greve - vitória das forças democráticas, alcançada em grande medida pelo esforço da bancada comunista -, sem, contudo, ter sido tal direito regulamentado na Carta Magna, como defenderam sempre os comunistas. 
A denúncia enérgica dos atos repressivos que, desde o início dos trabalhos da Constituinte, foram desencadeados contra os trabalhadores e os setores populares e democráticos pelas autoridades policiais e governamentais, constituiu uma linha permanente da atuação de Prestes e dos deputados comunistas. São inúmeros os pronunciamentos em que tais posicionamentos aparecem, destacando-se, por exemplo, os protestos contra o fechamento da Juventude Comunista (Braga, 2003, p. 562), assim como a denúncia da inconstitucionalidade da cassação do registro do PCB (Braga, 2003, p. 751). O último discurso de Prestes, pronunciado no Senado a 20 de outubro de 1947, foi dedicado à denúncia de prisões efetuadas no estado de Alagoas (Braga, 2003, p. 759-762).

Entre os pronunciamentos de Prestes na Constituinte, destacase o discurso proferido a 23 de março de 1946, em que o senador comunista viria a reiterar posição assumida dias antes em sabatina pública, quando, perguntado "qual a posição dos comunistas se o Brasil acompanhasse qualquer nação imperialista que declarasse guerra à União Soviética", respondera:

Faríamos como o povo da Resistência Francesa, o povo italiano, que se ergueu contra Petain e Mussolini. Combateríamos uma guerra imperialista contra a URSS e empunharíamos armas para fazer a resistência em nossa pátria, contra um governo desses, retrógrado, que quisesse a volta do fascismo. Se algum governo cometesse esse crime, nós, comunistas, lutaríamos pela transformação da guerra imperialista em guerra de libertação nacional (Braga, 2003, p. 88).

Enfrentando, na Constituinte, toda sorte de provocações de caráter anticomunista - e até mesmo de raivosas agressões verbais por parte de seus adversários, Prestes, nesse discurso, faz a enérgica denúncia do que ele denomina de "campanha de preparação para a guerra", alertando para a existência de "um sistema organizado de provocação e preparação psicológica para a guerra" (Braga, 2003, p. 130). É o momento em que, após o célebre discurso de Winston Churchill em Fulton, a 5 de março de 1946, a chamada Guerra Fria era desencadeada pelas potências imperialistas. Distintamente do que as versões eivadas de anticomunismo procuraram consagrar, frente aos apartes provocativos de Juraci Magalhães e demais elementos anticomunistas com assento na Constituinte, Prestes, nesse memorável discurso, deixa claro que os ataques desferidos contra ele pessoalmente e contra o PCB são parte de uma campanha de proporções internacionais, movida pelas nações imperialistas com o objetivo de provocar a guerra, pretendendo assim deter o avanço do sistema socialista, que havia saído fortalecido com a vitória dos Aliados sobre o nazifascismo. 
Na impossibilidade de abordar a multiplicidade de questões levantadas pela bancada comunista durante sua atividade parlamentar, cabe assinalar que a atuação do PCB na Constituinte de 1946 contém ensinamentos importantes para quem se interessa pela história dos comunistas brasileiros, mas também constitui valiosa experiência para as forças democráticas e progressistas no Brasil de hoje.

\section{Referências}

BENEVIDES [1981], Maria Victoria de Mesquita. A UDN e o Udenismo: ambigüidades do liberalismo brasileiro (1945-1965). São Paulo: Paz e Terra.

BRAGA [2003], Sérgio Soares (org.). Luiz Carlos Prestes: o Constituinte, o Senador (1946-1948). Brasília: Senado Federal/Conselho Editorial (Edições do Senado Federal, vol. 10).

CARONE [1976], Edgard. A Terceira República (1937-1945). São Paulo: DIFEL.

CARONE [1977], Edgard. O Estado Novo (1937-1945). (1ª reimpressão) São Paulo: DIFEL.

CARONE [1982], Edgard. O P. C. B. (1943 a 1964) (V. 2). São Paulo: DIFEL.

CARONE [1985], Edgard. A República Liberal - II - evolução política (1945-1964). São Paulo: DIFEL.

CORSI [2000], Luiz Francisco. Estado Novo: política externa e projeto nacional. São Paulo: UNESP/FAPESP.

GOMES [1988], Ângela de Castro. A Invenção do Trabalhismo. Rio de Janeiro: IUPERJ.

PRESTES [2001], Anita Leocadia. Da Insurreição Armada (1935) à "União Nacional" (1938-1945): a virada tática na política do PCB. São Paulo: Paz e Terra.

PRESTES [s. d.], Luiz Carlos Problemas Atuais da Democracia. Rio de Janeiro: Editora Vitória.

SEGATTO [1982], José Antônio et al. PCB: Memória fotográfica (1922-1982). São Paulo, Brasiliense.

SILVA [1976], Hélio. 1945: Por que Depuseram Vargas. Rio de Janeiro: Civilização Brasileira. 